\title{
Pollinator and Herbivore Attraction to Cucurbita Floral Volatiles
}

\author{
Elizabeth S. Andrews • Nina Theis • Lynn S. Adler
}

Received: 23 March 2007 / Revised: 1 June 2007 / Accepted: 18 June 2007 /

Published online: 21 July 2007

(C) Springer Science + Business Media, LLC 2007

\begin{abstract}
Mutualists and antagonists may place conflicting selection pressures on plant traits. For example, the evolution of floral traits is typically studied in the context of attracting pollinators, but traits may incur fitness costs if they are also attractive to antagonists. Striped cucumber beetles (Acalymma vittatum) feed on cucurbits and are attracted to several volatiles emitted by Cucurbita blossoms. However, the effect of these volatiles on pollinator attraction is unknown. Our goal was to determine whether pollinators were attracted to the same or different floral volatiles as herbivorous cucumber beetles. We tested three volatiles previously found to attract cucumber beetles in a factorial design to determine attraction of squash bees (Peponapis pruinosa), the specialist pollinators of cucurbita species, as well as the specialist herbivore $A$. vittatum. We found that 1,2,4-trimethoxybenzene was attractive to both the pollinator and the herbivore, indole was attractive only to the herbivore, and $(E)$ cinnamaldehyde was attractive only to the pollinator. There were no interactions among volatiles on attraction of squash bees or cucumber beetles. Our results suggest that reduced indole emission could benefit plants by reducing herbivore attraction without loss of pollination, and that 1,2,4-trimethoxybenzene might be under conflicting selection pressure from mutualists and antagonists. By examining the attraction of both mutualists and antagonists to Cucurbita floral volatiles, we have demonstrated the potential for some compounds to influence only one type of interaction, while others may affect both interactions and possibly result in tradeoffs. These results shed light on the potential evolution of fragrance in native Cucurbita, and may have consequences for yield in agricultural settings.
\end{abstract}

Keywords Acalymma vittatum $\cdot$ Cucurbita $\cdot($ E)-cinnamaldehyde $\cdot$ Floral volatiles Herbivore $\cdot$ Indole $\cdot$ Peponapis pruinosa $\cdot$ Pollinator $\cdot 1,2,4$-Trimethoxybenzene

E. S. Andrews $\cdot$ N. Theis $\cdot$ L. S. Adler $(\square)$

Department of Plant, Soil and Insect Sciences, University of Massachusetts, Amherst, MA 01003, USA e-mail: 1sadler@ent.umass.edu 


\section{Introduction}

Interactions among plants, their herbivores, and their pollinators are thought to have led to the diversification of both plants and insects (e.g., Becerra 1997; Farrell and Mitter 1998; Dodd et al. 1999). Historically, studies of plant-herbivore and plant-pollinator interactions have focused either on pollinator attraction to floral traits or herbivore deterrence by plant defenses. However, most plants interact simultaneously with a variety of pollinators and herbivores that could exert reinforcing or conflicting selection pressure on plant traits (Strauss and Whittall 2006; Adler 2007) The study of pair-wise interactions in isolation may not give us an adequate understanding of the costs and benefits of phenotypic traits that mediate interactions with both herbivores and pollinators (Gomez and Zamora 2000; Herrera 2000; Adler et al. 2006).

An increasing number of studies have demonstrated that floral display and rewards may attract antagonists as well as mutualists. For example, wider corollas have made Polemonium viscosum flowers more attractive to pollinators but also more vulnerable to ant nectar thieves (Galen and Cuba 2001), and Ipomopsis aggregata plants with larger inflorescences attract higher rates of predispersal seed predation (Brody and Mitchell 1997). Hermaphrodites of Fragaria virginiana experience more herbivory by the bud-clipping weevil Anthonomus signatus compared to female morphs, and this difference is thought to be due to pollen rewards offered by hermaphrodites (Ashman et al. 2004a). Greater nectar rewards in Datura stramonium increased oviposition of herbivorous larvae by pollinating hawkmoths (Adler and Bronstein 2004). Therefore, attracting pollinators without also attracting herbivores may be a challenge for flowering plants that require animal pollinators to reproduce.

Scent plays a near-ubiquitous role in plant-insect interactions. Plant volatiles can attract pollinators, provide learning cues for foraging insects, serve as herbivore repellants or attractants, or attract natural enemies of herbivores (De Moraes et al. 1998; Pichersky and Gershenzon 2002; Cunningham et al. 2004; Ashman et al. 2005; Huber et al. 2005). Despite the many ways that scent influences interactions between plants and insects, we know relatively little about how herbivores and pollinators respond to the same scent volatiles. Such information may provide insight into the evolution of the composition, strength, and timing of scent emission. For example, both Cirsium arvense and Nicotiana attenuata have high floral volatile emission rates during peak reproductive periods that decline after pollination, suggesting a possible cost to emission after pollination is effected (Euler and Baldwin 1996; Theis and Raguso 2005; Theis et al. 2007). However, there are few data to assess the costs and benefits of scent emission in most systems.

Our study addressed the role of floral scent mediating interactions among squash plants, their herbivores, and their pollinators. Most Cucurbita species are monoecious, rely on pollinator visitation for reproduction, and are often pollinated by specialist squash bees (Hurd et al. 1974). Several floral volatiles from Cucurbita blossoms are attractive to many species of herbivorous cucumber beetles (Andersen and Metcalf 1986; Lampman and Metcalf 1987; Lewis et al. 1990; Metcalf et al. 1995). However, the effect of these volatiles on pollinator attraction is unknown. The goal of this study was to determine whether pollinators and cucumber beetles were attracted to the same floral volatiles to provide a greater understanding of how mutualistic and antagonistic interactions may affect reproductive fitness and selection on Cucurbita floral scent.

\section{Methods and Materials}

Study System and Site The study was conducted in a butternut squash field located in the town of Dighton, Bristol County, in southeastern Massachusetts, USA (41 $\left.{ }^{\circ} 49^{\prime} 06.65^{\prime \prime} \mathrm{N}, 7^{\circ} 07^{\prime} 57.19^{\prime \prime} \mathrm{W}\right)$. 
Cucurbita moschata Duchesne (butternut squash, Cucurbitaceae) is an annual broad-leaved vine crop. Plants are monoecious with separate male and female flowers that last for 1 day, opening before sunrise and wilting by early afternoon (McGregor 1976). The scent of male and female Cucurbita blossoms attracts Acalymma vittatum Fabricius (striped cucumber beetle, Chrysomelidae) (Andersen and Metcalf 1986; Lewis et al. 1990; Metcalf and Lampman 1991; Metcalf et al. 1995; Granero et al. 2004; Ferrari et al. 2006), a specialist herbivore that is responsible for extensive damage to northeastern cucurbit crops (Hoffmann et al. 1996). Leaves and roots of some Cucurbita species also produce volatiles that may attract cucumber beetles and other insects (Peterson et al. 1994; Cosse and Baker 1999). However, we focused on floral volatiles because these are most likely to be attractive to pollinators as well as herbivores.

Acalymma vittatum overwinters as adults in diapause that emerge in late spring, feed on cotyledons and new leaves, and then oviposit in early summer. Larvae are specialists on cucurbit roots. The next generation of adults emerges in midsummer and feeds on cucurbit leaves, blossoms, and fruit (Metcalf and Metcalf 1992). Cucumber beetles are often found in cucurbit flowers, where they feed on pollen and floral tissue (Bach 1977; Andersen and Metcalf 1986, 1987; Metcalf and Metcalf 1992).

The squash bee Peponapis pruinosa Say (squash bee, Apidae) is one of the most abundant pollinators of squash and pumpkin (Hurd et al. 1974; Shuler et al. 2005). This specialist species collects pollen exclusively from Cucurbita blossoms (Hurd et al. 1974). Apis mellifera L. (honeybee, Apidae) pollinates cucurbits but does not have a particular affinity (Shuler et al. 2005). Other pollinators that visit Cucurbita crops include Bombus spp. Latreille (bumblebee, Apidae), various halictid species (Lasioglossum spp., Agapostemon spp., and Augochlorinae, Halictidae), and Melissodes bimaculata Lepeletier (two-spotted miner bee, Apidae) (Shuler et al. 2005).

Treatments Three volatiles, 1,2,4-trimethoxybenzene (T hereafter, Sigma-Aldrich, St. Louis, MO, USA, T68802, 97\% pure), indole (I hereafter, Sigma-Aldrich, 13408, 99+\% pure), and (E)-cinnamaldehyde (C hereafter, Sigma-Aldrich, C80687, 99\% pure), are components of Cucurbita blossoms that, in combination, were attractive to A. vittatum in previous studies and have been used to monitor beetle abundance (Andersen and Metcalf 1986; Lewis et al. 1990; Metcalf et al. 1995). Our purpose was to determine whether these volatiles are also attractive to pollinators to assess whether plants might experience a tradeoff in terms of their ability to attract pollinators while deterring herbivores. The presence and absence of the three volatiles was manipulated in a $2 \times 2 \times 2$ factorial design for a total of eight combinations. For each treatment, volatiles were placed separately onto cotton wicks in $20-\mu$ lamounts and were applied additively to follow the method of Lewis et al. (1990). Due to its solid state at room temperature, $20 \mathrm{mg}$ of I was dissolved in $20 \mu \mathrm{l}$ of acetone. Acetone was not used for the other volatiles, which were liquids. Therefore, we used two control treatments, $20 \mu \mathrm{l}$ of acetone and a dry cotton wick, for a total of nine treatments.

Emission rates vary widely within and among species, and our treatment emission rate is approximately 100-fold higher than what is emitted from various Cucurbita on a daily basis (Andersen and Metcalf 1987; Theis, Adler, and Hazzard, personal observation). These rates may be high, but they were selected to mirror those used previously (Lewis et al. 1990). Further, A. vittatum attraction had a tightly positive log-linear response to concentrations of both indole and TIC between 0.3 and $30 \mathrm{mg}$ per trap (Lewis et al. 1990). While the slope of the response was higher for TIC than indole, this suggests that beetle response may change in magnitude, but not direction, due to higher concentrations of volatiles. However, similar dose-response curves have not been conducted for $P$. pruinosa. There was $20 \mu \mathrm{l}$ of volatile 
in treatments with a single component ( $\mathrm{T}$, I, and $\mathrm{C}$ alone), $40 \mu \mathrm{l}$ of total volatile in treatments with two components $(\mathrm{T}+\mathrm{I}, \mathrm{T}+\mathrm{C}, \mathrm{I}+\mathrm{C})$, and $60 \mu \mathrm{l}$ of total volatiles in treatments with all three components $(\mathrm{T}+\mathrm{I}+\mathrm{C})$. The processing of mixtures of distinct volatiles in the insect brain appears to be close to additive, or even slightly suppressive (Deisig et al. 2006), and so the increase in total volatiles in the combined treatments should not by itself increase attraction.

Trap Design Based on preliminary tests of white, silver, and yellow bowls (Solo Cup, Highland Park, IL, USA) in two sizes (540 ml vs. 4.8 1), we selected yellow (stock no. SPB18), to serve as the trap base because it attracted the most insects (data not shown), which is consistent with previous research using other trap types (Hoffmann et al. 1996). Preliminary trapping indicated that bowl size did not affect insect trapping (data not shown), so the 540-ml bowls were used because they were similar in size to a butternut squash flower. Traps were composed of a bowl with a $20-\mathrm{ml}$ scintillation vial attached to the bottom with silicone-based glue (Permatex, clear RTV silicone adhesive sealant, model 66B, Permatex, Hartford, CT, USA). A 2-ml graduated microcentrifuge tube was placed inside the 20-ml vial. A piece of cotton roll (TIDI Brand, nonsterile, \#2-medium, TIDI Products, Neenah, WI, USA) was cut to $3 \mathrm{~mm} \times 1 \mathrm{~cm}$ and placed into each centrifuge tube. Traps were filled with $520 \mathrm{ml}$ of a soap-water solution (unscented Dawn ${ }^{\circledR}$ soap, Proctor and Gamble, Cincinnati, OH, USA).

Experimental Design Twenty-seven traps were placed in the field on July 26, 2005. Traps were arranged in three blocks, each of which was a row that included one trap in each treatment combination. Traps within blocks were approximately $3 \mathrm{~m}$ apart, alternating every other plant, and positioned underneath a broad leaf to protect from rain and mimic flower position. Volatiles were replaced everyday between 1800 and 1900 hours, just before sunset, which allowed us to monitor squash bee pollinators that began to forage before sunrise (Hurd et al. 1974). To avoid bias due to edge or positional effects, traps were moved over one position within the block each day.

Insect Collection and Identification Insects were collected on two separate dates, July 31 and August 4, so that each collection represented multiple days of cumulative insect trapping. Butternut squash plants began to bloom on July 31, reducing the number of pollinators found in traps in the second collection. Insects were cleaned and dried following a protocol from the USDA Bee Biology and Systematics Laboratory (2002). Pollinators were identified to genus using Michener et al. (1994) and to species using Mitchell (1960, 1962).

Data Analysis The number of P. pruinosa and A. vittatum per trap were used as response variables in separate analyses. Other insects were not caught in sufficient numbers to be analyzed (see "Results" section, "Insect Composition and Abundance" subsection). The two controls (acetone vs. no solvent) were combined into one treatment because there was no difference between them for either insect group $\left(F_{1,11}<0.1, P>0.75\right.$ for A. vittatum; no $P$. pruinosa caught in either control). We then determined the effect of $\mathrm{T}$, I, and $\mathrm{C}$ as fixed main effects (presence/absence of each), their interactions, block, and collection date on $P$. pruinosa and $A$. vittatum abundance by using separate ANOVAs. Trap was the unit of replication. The number of $A$. vittatum was $\log (x+1)$ transformed to meet assumptions of normality; P. pruinosa abundance was normal without transformation. Mean position was used as a covariate for the pollinator analysis but dropped from the beetle analysis because it was not significant. All analyses were performed with SAS v. 9.1. 
We expect that synergistic effects of individual compounds will be reflected by significant interaction terms in our ANOVA analysis. However, synergism was defined by Metcalf et al. (1995) as a trap catch that is more than the additive components of the mixture, and they reported the synergistic ratios (SR). SR is the ratio of the mean trap catch of the mixture (minus the control) to the total mean trap catches of each component in isolation (minus the control). We have calculated these values as well.

\section{Results}

Insect Composition and Abundance The primary pollinator trapped was $P$. pruinosa $(75 \%$ of all bees). Apis mellifera (3.3\%), Bombus spp. (1.7\%), M. bimaculata (6.6\%), Halictus rubicundus Christ (Halictidae, 1.7\%), Halictus ligatus Say (Halictidae, 5\%), Augochlorella striata Provancher (1.7\%), and Lasioglossum spp. (5\%) were also collected from the traps. Acalymma vittatum ( $62.7 \%$ of all beetles) was the primary beetle trapped, followed by Cyclocephala borealis (northern masked chafer, Scarabaeidae, 34\%) and click beetles (Elateridae, 3.3\%).

Beetle Attractants Acalymma vittatum was significantly attracted to T and I (Table 1). There were 2.7 times as many $A$. vittatum caught in traps baited with T compared to traps without $\mathrm{T}$, and traps baited with I were 3.3 times more attractive than those without (Fig. 1a). C was not attractive to $A$. vittatum. The effect of the volatiles on $A$. vittatum attraction was additive; there were no significant interactions. However, the combination of TIC trapped twice as many beetles as $\mathrm{T}+\mathrm{I}+\mathrm{C}$ (SR ratio 2.0; Fig. 2a). Other combinations did not appear to be more attractive than the summation of single components (TI vs. T + I: SR ratio 1.2; TC vs. $\mathrm{T}+\mathrm{C}$ : SR ratio 0.4 ; IC vs. I + C: SR ratio 0.1; see Fig. 2a for visual comparisons).

Pollinator Attractants Peponapis pruinosa was significantly attracted to T and C, but not to I (Table 2, Fig. 1b). Traps baited with T attracted 2.7 times more $P$. pruinosa than those without $\mathrm{T}$, and traps baited with $\mathrm{C}$ were 3.8 times more attractive than those without. There were no interactive effects of any volatiles on pollinator attraction, and the SR ratio was between 0.4 and 1.1 for all volatile combinations (Fig. 2b).

Table 1 Effects of floral volatiles on the number of $A$. vittatum collected in traps
${ }^{\text {a }}$ Significant $P$ values are shown in bold.

\begin{tabular}{lllll}
\hline Source & df & SS & $F$ & $P^{\mathrm{a}}$ \\
\hline $\mathrm{T}$ & 1 & 6.53 & 15.05 & $<\mathbf{0 . 0 0 1}$ \\
$\mathrm{I}$ & 1 & 8.79 & 20.27 & $<\mathbf{0 . 0 0 1}$ \\
$\mathrm{C}$ & 1 & 0.01 & 0.02 & 0.888 \\
$\mathrm{~T} \times \mathrm{I}$ & 1 & 1.11 & 2.56 & 0.117 \\
$\mathrm{~T} \times \mathrm{C}$ & 1 & 0.09 & 0.21 & 0.649 \\
$\mathrm{I} \times \mathrm{C}$ & 1 & 0.34 & 0.78 & 0.382 \\
$\mathrm{~T} \times \mathrm{I} \times \mathrm{C}$ & 1 & 0.44 & 1.02 & 0.319 \\
Block & 2 & 1.32 & 1.52 & 0.230 \\
Date & 1 & 10.89 & 25.12 & $<\mathbf{0 . 0 0 1}$ \\
Error & 43 & 18.65 & - & - \\
\hline
\end{tabular}


Fig. 1 Mean number of $A$. vittatum (a) and $P$. pruinosa (b) collected per trap with each volatile treatment. Significant data at $P<0.05$ are indicated by asterisks; non-significant data are indicated by NS. Error bars represent standard error
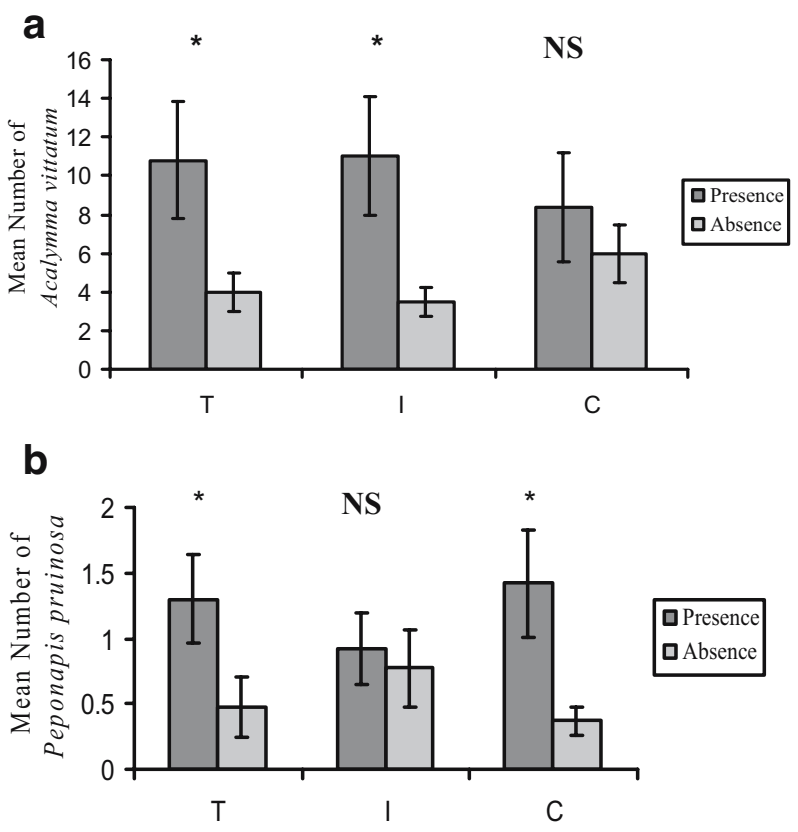

\section{Discussion}

We found that each of the three volatiles tested had different effects on the attraction of pollinators and herbivores. (E)-cinnamaldehyde was attractive to the pollinator $P$. pruinosa but not the herbivore $A$. vittatum, indole was attractive to $A$. vittatum but not $P$. pruinosa, and 1, 2, 4-trimethoxybenzene was attractive to both (Fig. 1). Because Cucurbita rely on pollinators for reproduction (McGregor 1976), the attraction of pollinators has fitness consequences. Furthermore, A. vittatum and related diabroticite beetles can have

Fig. 2 Number of $A$. vittatum (a) and $P$. pruinosa (b) caught in traps baited with single volatiles (T, I, or C) as compared to combinations $(\mathrm{T}+\mathrm{IC}, \mathrm{C}+\mathrm{TI}, \mathrm{I}+$ $\mathrm{TC}$, or TIC together) to illustrate potential synergistic effects

\section{a}

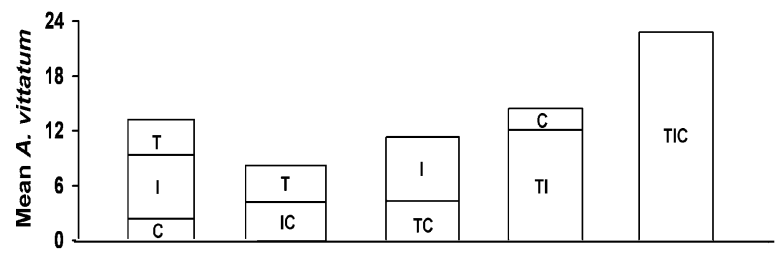

Combinations of Treatments

b

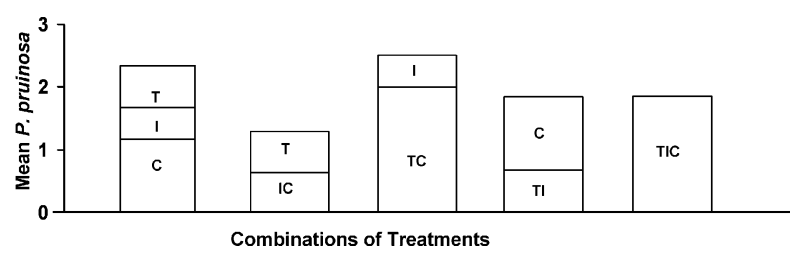


Table 2 Effects of floral volatiles on the number of $P$. pruinosa collected in traps in bold.

\begin{tabular}{lllll}
\hline Source & df & SS & $F$ & $P^{\mathrm{a}}$ \\
\hline $\mathrm{T}$ & 1 & 6.87 & 4.64 & $\mathbf{0 . 0 3 7}$ \\
$\mathrm{I}$ & 1 & 0.003 & 0.00 & 0.960 \\
$\mathrm{C}$ & 1 & 12.36 & 8.35 & $\mathbf{0 . 0 0 6}$ \\
$\mathrm{T} \times \mathrm{I}$ & 1 & 0.9 & 0.61 & 0.440 \\
$\mathrm{~T} \times \mathrm{C}$ & 1 & 0.6 & 0.41 & 0.527 \\
$\mathrm{I} \times \mathrm{C}$ & 1 & 0.36 & 0.24 & 0.626 \\
$\mathrm{~T} \times \mathrm{I} \times \mathrm{C}$ & 1 & 0.23 & 0.16 & 0.696 \\
Block & 2 & 2.94 & 0.99 & 0.379 \\
Date & 1 & 17.46 & 11.79 & $\mathbf{0 . 0 0 1}$ \\
Mean position & 1 & 12.3 & 8.31 & $\mathbf{0 . 0 0 6}$ \\
Error & 42 & 16.18 & - & - \\
\hline
\end{tabular}

devastating effects on cucurbit growth, reproduction, and survival (Metcalf and Metcalf 1992; Hoffmann et al. 1996). Thus, the attraction of both pollinators and cucumber beetles is likely to have fitness consequences for native cucurbits and implications for crop yield in managed cucurbit systems.

While a growing number of studies have demonstrated that floral display or reward can be costly due to the attraction of antagonists (Brody and Mitchell 1997; Adler and Bronstein 2004; Ashman et al. 2004b; Strauss and Irwin 2004), the current study is one of few to address the role of scent in attracting pollinators compared to herbivores. Similar to our study, specific floral volatiles present in $C$. arvense scent attracted just pollinators, just herbivores, or both pollinators and herbivores (Theis 2006). In addition to having two different corolla shapes, $P$. viscosum has two distinct scent morphs that attract different types of pollinators depending on the presence of floral antagonists (Galen et al. 1987; Galen and Cuba 2001). In areas with low populations of nectar-robbing ants, $P$. viscosum flowers have a wide corolla and a sweet scent that attracts bumblebee pollinators. In areas with high ant populations, flowers have a narrow corolla that deters ants, at the cost of attracting bumblebee pollinators. These flowers emit a skunky scent that attracts fly pollinators that can fit in the narrow corolla.

We found that $A$. vittatum was attracted to 1,2,4-trimethoxybenzene and indole, but not (E)-cinnamaldehyde, and that there were no interactive effects of volatiles on attraction. This is contrary to what was observed by Lewis et al. (1990), who found in a field study in Illinois that $A$. vittatum was attracted to indole and $(E)$-cinnamaldehyde, but not 1,2,4trimethoxybenzene. Similar to their result, we found the combination of TIC to be more attractive than the sum of the parts, with an SR ratio of 2.0. However, our statistical analysis (factorial rather than one-way ANOVA) suggests that this difference is not significant. There are a number of potential explanations for the disparity between our results and those of Lewis et al. (1990). For example, there are many differences in habitat, including microclimate, soil type, and vegetation, between Massachusetts and Illinois. Experimental outcomes can vary over space and time (e.g., Thompson and Cunningham 2002), and the differences between our results and those of Lewis et al. (1990) suggests that this may be the case for the response of $A$. vittatum to Cucurbita floral volatiles.

While this research was conducted in an agricultural setting, our results could be relevant to wild cucurbit systems. Native Cucurbita species, such as C. pepo subsp. texana in the southwestern USA, are pollinated by squash and gourd bees of the genus Peponapis (Hurd et al. 1971) and are fed upon by A. vittatum and other species of diabroticite beetles (Quesada et al. 1995). Pollinators and herbivores could exert different selective pressures on 
floral scent, which may influence the evolution of scent composition. Further research could involve manipulative field experiments with $C$. pepo subsp. texana in its native habitat to determine if changes in scent volatiles cause appreciable differences in herbivory, pollination, and plant reproduction. Such research should also address the role of scent concentration, which was relatively high in our study, to determine if lower levels that reflect natural blossom emission have similar effects on attraction of both pollinators and herbivores.

Our findings could have important implications for the cucurbit industry. Cucurbita fragrance components were not attractive to all visiting specialist insects. For example, we found that only pollinators are attracted to $(E)$-cinnamaldehyde and only herbivores were attracted to indole. The next step would be to determine whether incremental changes in these volatiles lead to differential attraction of pollinators or herbivores. However, there could be unanticipated consequences of a manipulation in volatile levels if these compounds have important functions in other plant parts (e.g., De Moraes et al. 1998). On the other hand, if variation in scent led to increases in pollination or decreases in damage, plant breeders might benefit from selecting plants that produce more $(E)$-cinnamaldehyde or less indole. Decreasing herbivory without the use of pesticides might have the added benefit of limiting damage to local bee populations (Allen-Wardell et al. 1998).

Acknowledgements We thank T'ai Roulston of the Department of Environmental Sciences at the University of Virginia for identifying pollinators, Araujo Farms in Dighton, MA, for the use of their butternut squash field, and S. Halpern, T. Roulston, and two anonymous reviewers for comments on the manuscript. This research was supported by a University of Massachusetts Amherst senior honors research grant awarded by the Commonwealth College to ESA, the National Science Foundation DEB 0542819 to NT, and a Northeastern Integrated Pest Management USDA grant to LSA.

\section{References}

ADLER, L. S. 2007. Selection by pollinators and herbivores on attraction and defense, in K. J. Tilmon (ed.). Specialization, Speciation and Radiation: The Evolutionary Biology of Herbivorous Insects. University of California Press, Berkley (in press).

AdLER, L. S., and BRONSTEIN, J. L. 2004. Attracting antagonists: Does floral nectar increase leaf herbivory? Ecology 85:1519-1526.

Adler, L. S., WinK, M., Distl, M., and LenTZ, A. J. 2006. Leaf herbivory and nutrients increase nectar alkaloids. Ecol. Lett. 9:960-967.

Allen-Wardell, G., Bernhardt, P., Bitner, R., Burquez, A., Buchmann, S., Cane, J., Cox, P. A., Dalton, V., Feinsinger, P., Ingram, M., Inouye, D., Jones, C. E., Kennedy, K., Kevan, P., Koopowitz, H., Medellin, R., Medellin-morales, S., Nabhan, G. P., Pavlik, B., Tepedino, V., Torchio, P., and WALKER, S. 1998. The potential consequences of pollinator declines on the conservation of biodiversity and stability of food crop yields. Conserv. Biol. 12:8-17.

Andersen, J. F. and MetCAlf, R. L. 1986. Identification of a volatile attractant for Diabrotica (Coleoptera, Chrysomelidae) and Acalymma (Coleoptera, Chrysomelidae) spp from blossoms of Cucurbita maxima Duchesne. J. Chem. Ecol. 12:687-699.

Andersen, J. F. and MetCALF, R. L. 1987. Factors influencing distribution of Diabrotica spp (Coleoptera, Chyrsomelidae) in blossoms of cultivated Cucurbita spp. J. Chem. Ecol. 13:681-699.

Ashman, T. L., Bradburn, M., Cole, D. H., Blaney, B. H., and Raguso, R. A. 2005. The scent of a male: The role of floral volatiles in pollination of a gender dimorphic plant. Ecology 86:2099-2105.

Ashman T.L., Cole, D. H., and BradBuRn, M. 2004a. Sex-differential resistance and tolerance to herbivory in a gynodioecious wild strawberry. Ecology 85:2550-2559.

Ashman T. L., Knight, T. M., Steets, J. A., Amarasekare, P., Burd, M., Campbell, D. R., Dudash, M. R., Johnston, M. O., Mazer, S. J., Mitchell, R. J., Morgan, M. T., and Wilson, W. G. 2004b. Pollen limitation of plant reproduction: Ecological and evolutionary causes and consequences. Ecology $85: 2408-2421$. 
BACH, C. E. 1977. Distribution of Acalymma vittata and Diabrotica virgifera (Coleoptera: Chrysomelidae) on cucurbits. The Great Lakes Entomologist 10:123-125.

BECERRA, J. X. 1997. Insects on plants: Macroevolutionary chemical trends in host use. Science 276:253256.

BRODY, A. K. and MitcheLL, R. J. 1997. Effects of experimental manipulation of inflorescence size on pollination and pre-dispersal seed predation in the hummingbird-pollinated plant Ipomopsis aggregata. Oecologia 110:86-93.

COSSE, A. A. and BAKER, T. C. 1999. Electrophysiologically and behaviorally active volatiles of buffalo gourd root powder for corn rootworm beetles. J. Chem. Ecol. 25:51-66.

Cunningham, J. P., Moore, C. J., ZALuCKI, M. P., and WeSt, S. A. 2004. Learning, odour preference and flower foraging in moths. J. Exp. Biol. 207:87-94.

De Moraes, C. M., Lewis, W. J., Pare, P. W., Alborn, H. T., and Tumlinson, J. H. 1998. Herbivoreinfested plants selectively attract parasitoids. Nature 393:570-573.

Deisig, N., GiURFA, M., LACHNIT, H., and SANDOZ, J. C. 2006. Neural representation of olfactory mixtures in the honeybee antennal lobe. Eur. J. Neurosci. 24:1161-1174.

DodD, M. E., Silvertown, J., and ChaSe, M. W. 1999. Phylogenetic analysis of trait evolution and species diversity variation among angiosperm families. Evolution 53:732-744.

Euler, M. and BALDwin, I. T. 1996. The chemistry of defense and apparency in the corollas of Nicotiana attenuata. Oecologia 107:102-112.

FARrell, B. D. and MitTeR, C. 1998. The timing of insect/plant diversification: Might Tetraopes (Coleoptera : Cerambycidae) and Asclepias (Asclepiadaceae) have co-evolved? Biol. J. Linn. Soc. 63:553-577.

Ferrari, M. J., Stephenson, A. G., Mescher, M. C., and De Moraes, C. M. 2006. Inbreeding effects on blossom volatiles in Cucurbita pepo subsp texana (Cucurbitaceae). Am. J. Bot. 93:1768-1774.

Galen, C. and CuBA, J. 2001. Down the tube: Pollinators, predators, and the evolution of flower shape in the alpine skypilot, Polemonium viscosum. Evolution 55:1963-1971.

Galen, C., Zimmer, K. A., and Newport, M. E. 1987. Pollination in floral scent morphs of Polemonium viscosum - a mechanism for disruptive selection on flower size. Evolution 41:599-606.

GOMEZ, J. M. and ZAMORA, R. 2000. Spatial variation in the selective scenarios of Hormathophylla spinosa (Cruciferae). Am. Nat. 155:657-668.

Granero, A. M., GonZalez, F. J. E., Frenich, A. G., SanZ, J. M. G., and Vidal, J. L. M. 2004. Single step determination of fragrances in Cucurbita flowers by coupling headspace solid-phase microextraction lowpressure gas chromatography-tandem mass spectrometry. J. Chromatogr. A 1045:173-179.

HERRERA, C. M. 2000. Measuring the effects of pollinators and herbivores: Evidence for non-additivity in a perennial herb. Ecology 81:2170-2176.

Hoffmann, M. P., Robinson, R. W., Kyle, M. M., and Kirkwyland, J. J. 1996. Defoliation and infestation of Cucurbita pepo genotypes by diabroticite beetles. Hortscience 31:439-442.

Huber, F. K., Kaiser, R., SAUter, W., and Schiestl, F. P. 2005. Floral scent emission and pollinator attraction in two species of Gymnadenia (Orchidaceae). Oecologia 142:564-575.

Hurd, P. D., Linsley, E. G., and Michelbacher, A. E. 1974. Ecology of the squash and gourd bee, Peponapis pruinosa, on cultivated cucurbits in California (Hymenoptera: Apoidea). Smithson. Contrib. Zool. 168:1-17.

HuRd, P. D., Linsley, E. G., and WhitAKER, T. M. 1971. Squash and gourd bees (Peponapis, Xenoglossa) and the origin of the cultivated Cucurbita. Evolution 25:218-234.

LampMAN, R. L., and MetCALF, R. L. 1987. Multicomponent kairomonal lures for southern and western corn rootworms (Coleoptera, Chrysomelidae, Diabrotica spp). J. Ecol. Entomol. 80:1137-1142.

Lewis, P. A., LAmpman, R. L., and Metcalf, R. L. 1990. Kairomonal attractants for Acalymma vittatum (Coleoptera, Chrysomelidae). Environ. Entomol. 19:8-14.

McGREGOR, S. E. 1976. Insect pollination of cultivated crop plants. U.S. Department of Agriculure, Agricultural Research Service, Washington, D.C.

MetCalf, R. L. and Lampman, R. L. 1991. Evolution of diabroticite rootworm beetle (Chrysomelidae) receptors for Cucurbita blossom volatiles. Proc. Natl. Acad. Sci. U.S.A. 88:1869-1872.

Metcalf, R. L. and Metcalf, E. R. 1992. Plant Kairomones in Insect Ecology and Control. Chapman and Hall, New York.

MetCALF, R. L., LAMPMAn, R. L., and DEEMDiCKSON, L. 1995. Indole as an olfactory synergist for volatile kairomones for diabroticite beetles. J. Chem. Ecol. 21:1149-1162.

Michener, C. D., McGinley, R. J., and Danforth, B. N. 1994. The Bee Genera of North and Central America (Hymenoptera: Apoidea). Smithsonian Institution Press, Washington.

Mitchell, T. B. 1960. Bees of the eastern United States. N. C. Agric. Exp. Stn. Tech. Bull. 1:1-538.

Mitchell, T. B. 1962. Bees of the eastern United States. N. C. Agric. Exp. Stn. Tech. Bull. 2:1-557. 
Peterson, J. K., Horvat, R. J., and Elsey, K. D. 1994. Squash leaf glandular trichome volatilesIdentification and influence on behavior of female pickleworm moth Diaphania nitidalis (Stoll) (Lepidoptera, Pyralidae). J. Chem. Ecol. 20:2099-2109.

PICHERSKY, E., and GERSHENZON, J. 2002. The formation and function of plant volatiles: perfumes for pollinator attraction and defense. Curr. Opin. Plant Biol. 5:237-243.

QuesAdA, M., Bollman, K., and STEPHENSON, A. G. 1995. Leaf damage decreases pollen production and hinders pollen performance in Cucurbita texana. Ecology 76:437-443.

SHUler, R. E., Roulston, T. H., and FARRIS, G. E. 2005. Farming practices influence wild pollinator populations on squash and pumpkin. J. Econ. Entomol. 98:790-795.

STRAUSS, S. Y., and IRWIN, R. E. 2004. Ecological and evolutionary consequences of multispecies plantanimal interactions. Ann. Rev. Ecol. Evol. Syst. 35:435-466.

StRauss, S. Y. and WhitTALl, J. B. 2006. Non-pollinator agents of selection on floral traits, pp. 120-138, in L. D. Harder and S. C. H. Barrett, (eds.). Ecology and Evolution of Flowers. Oxford University Press, Oxford.

THEIS, N. 2006. Fragrance of Canada thistle (Cirsium arvense) attracts both floral herbivores and pollinators. J. Chem. Ecol. 32:917-927.

Theis, N. and Raguso, R. A. 2005. The effect of pollination on floral fragrance in thistles. J. Chem. Ecol. 31:2581-2600.

Theis, N., Lerdau, M., and Raguso, R. A. 2007. The challenge of attracting pollinators while evading floral herbivores: Patterns of fragrance emission in Cirsium arvense and Cirsium repandum (Asteraceae). Int. J. Plant Sci. 168:587-601.

Thompson, J. N., and CunNingham, B. M. 2002. Geographic structure and dynamics of coevolutionary selection. Nature 417:735-738.

USDA Bee Biology and Systematics Laboratory. 2002. Processing bees that have been stored in alcohol so that they look nice and fluffy once pinned. Logan, Utah. http://online.sfsu.edu/ beeplot/pdfs/washing\% 20bees.pdf. 